EESTI NSV TEADUSTE AKADEEMIA TOIMETISED. XVI KOIDE

KEEMIA * GEOLOOGIA, 1967, Nr. 4

ИЗВЕСТИЯ АКАДЕМИИ НАУК ЭСТОНСКОII ССР. ТОМ XVI

ХИМИЯ * ГЕОЛОГНЯ. 1967, 쇼 4

\author{
E. LIPPMAA, S. RANG, O. EISEN, T. PEHK
}

\title{
CARBON-13 CHEMICAL SHIFTS OF NORMAL ALKENES
}

E. LIPPMAA, S. RANG, O. EISEN, T. PEHK. SOSINIK-13 KEEMILISED NIHKED SIRGE AHELAGA ALKEENIDES

Э. ЛИППМАА, С. РАНГ, О. ЭНЗЕН, Т. ПЕХК. ХИМИЧЕСКИЕ СДВИГИ УГЛЕРОДА-ЗЗ
Н-АЛКЕНОВ

In addition to optical, mainly infrared spectra, proton spectra have been used to study the structure and electronic properties of alkenes $\left[{ }^{11},{ }^{12}\right]$ and alkanes [13]. Several useful relationships have been found, the spectral patterns of the methyl groups are characteristic of the chain branching and both methyl and methylene patterns are indicative of methylene chain length $\left[{ }^{13}\right]$, while the chemical shifts of the unsaturated and $\alpha$-protons are susceptible to geometric isomerism [11,12]. But the shift differences are erratic and small, 0.04 to $0.10 \mathrm{ppm}$ only and the most specific difference in spin-spin coupling constants for cis and trans isomers cannot usually be measured from the very complicated spectra. Even double resonance can in this case accomplish only partial simplification of these spectra [11] and it is just impossible to measure the chemical shifts of all different protons in pentenes and more complicated alkenes.

Carbon-13 spectra of unsaturated compounds have been actively investigated. The early results of Holm [1] showed that olefinic carbon nuclei absorb in the same region as aromatic carbons. In the absence of polar substituents the absorption falls into the very crowded region of 44 to $79 \mathrm{ppm}$ from $\mathrm{CS}_{2}$. Substituents cause additional shifts and the full range reaches from 38 to $114 \mathrm{ppm}\left[{ }^{2}\right]$. A systematic study of olefins has been reported by Friedel and Retcofsky $\left.{ }^{[}\right]$and using largely these results, it has been shown that for simple hydrocarbons the chemical shift of the unsaturated $\mathrm{sp}^{2}$-carbon atoms is a constitutive property that depends on the nearest neighbours only [4]. The chemical shifts of unsaturated carbon atoms in aliphatic compounds can be calculated using the additive parameters of Savitsky [4] with good results but large deviations from additivity occur in alicyclic and especially in rigid unsaturated molecules [6]. Little is known, about the chemical shifts of saturated carbon atoms in alkenes. The spectra of these methyl and methylene groups consist of many overlapping lines, placed close together, so that monoresonance spectra of the saturated part of even simple alkenes are usually quite structureless and no determination of chemical shifts is possible ([ $\left.{ }^{3}\right]$, Fig. 2; [ $\left.\left.{ }^{[}\right]\right)$.

Spin decoupling results in greatly simplified spectra with only one sharp line with many times enhanced peak value for each carbon atom $\left.{ }^{[5-7}\right]$. Even if these lines overlap, the doubled line intensity in this case allows exact assignments to be made. 
All alkenes were investigated as neat liquids and the experimental conditions were exactly the same as in [5]. As in the case of alkynes, the perturbing frequency was changed in each experiment and was adjusted for maximum decoupling of either the olefinic or saturated hydrogen atoms.

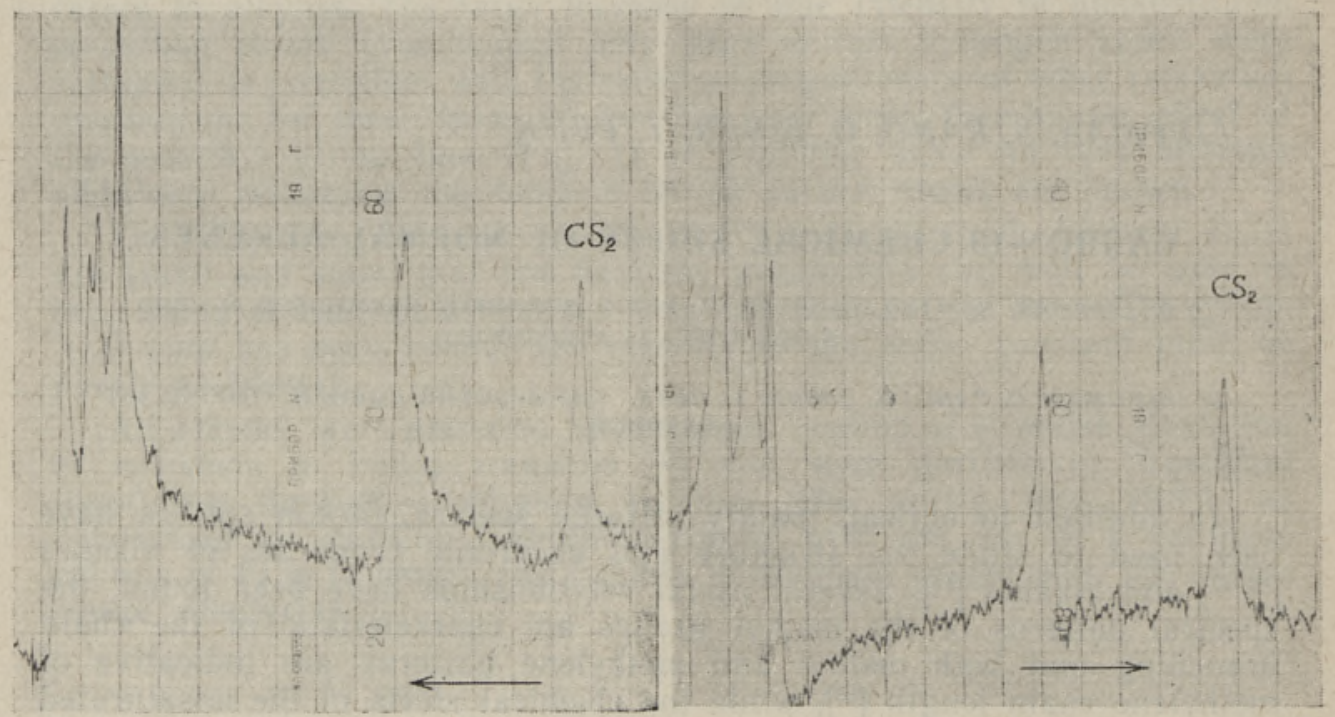

Fig. 1. Fast passage decoupled carbon-13 spectra of trans-octene-3, registered in two sweep directions.

Complete chemical shift data for the alkenes as well as the calculated values [ $\left.{ }^{4}\right]$ and the deviations are given in the table. The assignment of carbon chemical shifts to particular carbon atoms was made on the basis of regular deviations from the corresponding values in similar unsaturated or saturated compounds (n-octane), additive parameters $[4,7]$, peak intensities and through the use of selective decoupling with various $\Delta \omega_{2}$ values. The assignment of chemical shifts is not unambiguous for the unsaturated carbon atoms in 3 -octenes, where the selective $\gamma$-effect $\left[{ }^{7,10}\right]$ may change the relative shift order with respect to 2 -octenes. Since this specific effect is clearly absent in 4-octenes where the $\mathrm{sp}^{2}$-carbon shifts have quite usual values, the $\mathrm{sp}^{2}$-carbon shifts in 3 -octenes are assigned to conform with the general trend in this series.

The chemical shift data indicate that both the $\mathrm{sp}^{2}$ - and $\mathrm{sp}^{3}$-carbon shifts fall into the corresponding usual ranges [2]. In the case of asymmetrically placed double bonds in linear molecules, the difference of chemical shifts of the unsaturated carbon atoms has analytical significance. It is $24 \mathrm{ppm}$ in octene-1, $7 \mathrm{ppm}$ in octene-2 and $1.6 \mathrm{ppm}$ in octene-3. There is every reason to expect similar differences in higher alkenes. These differences are practically identical in both cis and trans isomers.

The chemical shifts of saturated carbon atoms show that the double bond influences the shielding of the immediate neighbours only and there is no selective effect on $\beta$ - or $\gamma$-carbon atoms. The shifts of these and other carbon atoms are very close to the corresponding shifts in paraffins. While other carbon chemical shifts can be calculated with 
acceptable accuracy, the $\alpha$-carbon atoms show large and significant deviations of very constant value. The chemical shifts of $\alpha$-carbon atoms in all cis-trans pairs differ by $5.7 \pm 1 \mathrm{ppm}$ and this difference depends neither on the type of the $\alpha$-carbon atom (methyl or methylene) nor on the position of the double bond in the molecule. The measured shift is larger than the calculated value in all cis-alkenes and smaller than that in all trans-alkenes. These deviations are with one exception much larger than the possible experimental error. In addition to the $\alpha$-carbons all carbon atoms, both saturated and unsaturated, show in cis-alkenes a small 1 to $2 \mathrm{ppm}$ diamagnetic shift relative to the corresponding atoms in trans-alkenes. This effect has also been noted for $\mathrm{sp}^{2}$-carbon atoms in 2 -butene $\left.{ }^{8}\right]$ and 3 -hexene [3]. The reason for this dependence of carbon chemical shifts on geometric isomerism is not clear. In the case of proton spectra of 1,2-substituted ethylenes the magnetic anisotropy of substituents has been suggested as a possible explanation [9], but this is not possible for the symmetrically placed $\mathrm{sp}^{2}$-carbon atoms. The

Carbon-13 chemical shift data for unbranched alkenes

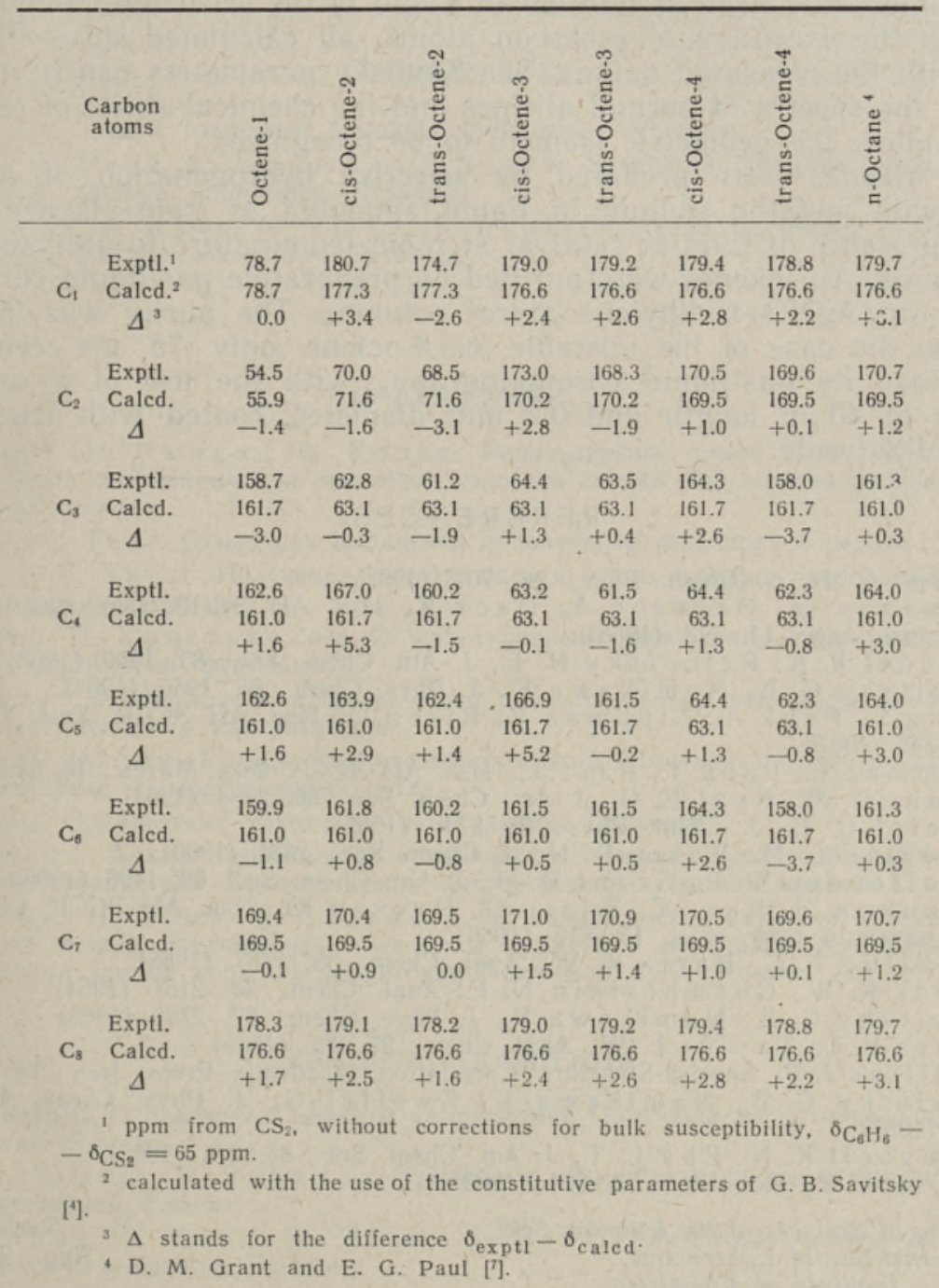


magnetic effects must be very small in unsubstituted normal alkenes, since the $\leqslant 0.05 \mathrm{ppm}$ differences of olefinic, $\alpha$-methyl and $\alpha$-methylene proton shifts in cis and trans isomers are nearly two orders of magnitude smaller than in carbon spectra, with opposite signs for $\alpha$-methyl and $\alpha$-methylene protons. Steric inhibition of conjugation, as suggested for bulky substituents [14] is quite improbable for the flexible alkyl groups where only hyperconjugation is possible, but some other forms of action through space $\left[{ }^{7,10}\right]$ cannot be entirely discounted. However, since all atoms of the molecule are affected a systematic difference in $\Delta E$ suggests itself. The only strong ultraviolet absorption band of normal alkenes is for cis-2-alkenes $\lambda_{\max }{ }^{c i s}=176.5+1.5 \mathrm{~m} \mu$ and for trans-2-alkenes $\lambda_{\max }{ }^{\text {trans }}=179 \pm 1 \mathrm{~m} \mu[15,16]$. If the paramagnetic contribution to the chemical shift ${\overline{\sigma_{\mathrm{p}}}}^{\mathrm{AA}}$ has in alkenes about the same value as in ethylene [19], then a $1.8 \mathrm{ppm} / \mathrm{m} \mu$ change in chemical shift values is to be expected and gives the right order of magnitude for the shift differences, although most of these are actually smaller. An analogous analysis of chemical shifts in cyclic ketones gave very similar results where the actual effect was likewise only about a half of the predicted value [17].

With the exception of $\alpha$-carbon atoms, all calculated shifts $\left[{ }^{4}\right]$ agree well with the measured values. The Savitsky parameters can be used to predict the spectra of normal alkenes and the chemical shifts of $\alpha$-carbon atoms allow the geometric isomers to be recognized.

All alkenes were prepared by selective hydrogenation of alkynes, either with metallic sodium in liquid ammonia to trans-alkenes [18] or in the presence of Lindlar catalyst at room temperature to predominantly cis alkenes. All alkenes were purified by preparative gas-liquid chromatography on $\mathrm{AgNO}_{3}$-triethylene glycol columns. The purity was 99.8 per cent (in the case of the unstable cis-4-octene only 75 per cent), as determined by gas-liquid chromatography with the use of a capillary column of $40 \mathrm{~m}$ length and $0.2 \mathrm{~mm}$ diameter, coated with triethylene glycol dibutyrate.

\section{REFERENCES}

1. Holm C. H., J. Chem. Phys., 26, 707 (1957).

2. Л иппм а а Ӭ., О ли всон А., П аст Я., Изв. АН ЭССР. Сер. физ.-матем. и техн. наук, 14, 473 (1965).

3. Friedel R. A.. Ret c of sky H. L., J. Am. Chem. Soc., 85. 1300 (1963).

4. Savitsky G. B., N a mik aw a K., J. Phys. Chem., 68, 1956 (1964).

5. Rang S., P e h k T., L i p pma a E., Eisen O., Изв. АН ЭССР. Хим., Геол. 16, 346 (1967).

6. L i p pm a E., Pehk T., P a st J., Изв. АН ЭССР. Физ., Матем., 16, 345 (1967).

7. Grant D. M., P a u 1 E. G., J. Am. Chem. Soc., 86, 2984 (1964).

8. Ma ci el G. E., J. Chem. Phys., 42, 2746 (1965).

9. J a ckm a n L. M., Wil e y R. H., J. Chem. Soc., 2881 (1960).

10. Woolfenden W. R., Gra nt D. M., J. Am. Chem. Soc., 88, 1496 (1966).

11. Липпм а а Э., Ранг С., Эйзен О., Пускар Ю., Изв. АН ЭССР. Сер. физ. матем. и техн, наук, 15, 615 (1966).

12. Stehling F. C., B a rtz K. W., Anal. Chem., 38, 1467 (1966).

13. B a rtz K. W., Chamberlain N. F., Anal. Chem., 36, 2151 (1964).

14. Savitsky G. B., N a m i k a w a K., J. Phys. Chem., 67, 2754 (1963).

15. J o nes L. C., T a y lor L. W., Anal. Chem., 27, 228 (1955).

16. P hilli ps J. P., Spectra-Structure Correlation, Academic Press, New York, 1964.

17. Savitsky G. B., N a mikaw a K., Z weifel G., J. Phys. Chem., 69, 3105 (1965).

18. C a m p bei1 K. N., E b y L. T., J. Am. Chem. Soc., 63, 216 (1941).

19. Pople J. A., Mol. Phys., 7, 301 (1963/64). 